\title{
9.2 The determination method of required modernization level of production's technical means at an enterprise
}

Abstract. The determination method of required modernization level of production's technical means at an enterprise, which provides an opportunity to formulate requirements for means of production when equipping an enterprise with means of production.

Key words: means of production, modernization, specifications, life in service.

\section{INTRODUCTION}

In order to maintain the level of its market share (or even increasing it) an industrial enterprise may employ several efforts, such as modernization. Only after modernization is it possible to expand production, increase efficiency, update technical means (TM) of production that are obsolete morally or physically, and so on. However, the decline in competitiveness is not the only factor that encourages renewal, in particular, the TM modernization. Also a significant factor is the financial income forgone, as it is impossible to be financially viable using the obsolete TM [451]-[453].

Modernization of modern production can be done in two ways: extensive and intensive. Extensive methods of modernization include increasing the number of shops, production lines, workers, machines, and so on. At the same time, the technology of production remains obsolete; new innovations are not implemented into a production process. Intensive ways of modernization include the improvement of the technological process through the introduction of modern technologies and methods of work, changes in the structure of the production enterprise [451].

In the practice of the TM of production development exist several methodological approaches to determine the required level of the TM modernization [454] - [457]. The most prevalent methods, which relay on the economic capabilities of the enterprise, are: based on known analogues or based on an available budget dedicated to modernization. In fact, the level of modernization should be determined based on the tasks inherent to the technical means, and the ability to effectively perform their own most important functions. Accordingly, the definition of the required level of modernization of TM 
should depend on the production potential of the enterprise and the ability of the enterprise to successfully perform its own task in the course of production activities.

\section{SUBSTANTIVE PROVISIONS}

The potential of production $\Pi$ of an enterprise is determined by a number

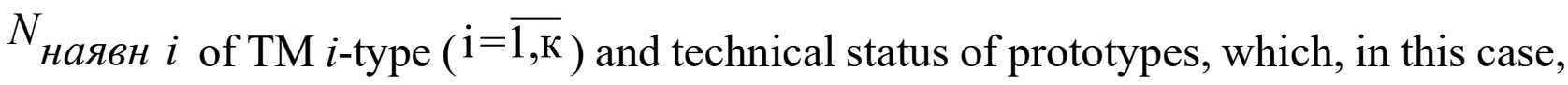
will be characterized by indicators of the technical level of TM of the enterprise, which to some extent depend in addition on their technical characteristics (TCh). The level of production capacity $\theta^{B U M}$ of an enterprise, associated with production potential through expression:

$$
\Pi_{O}^{B u M}=\Pi_{O} \cdot\left(\theta^{\text {Buм }}+\beta_{O} \cdot T\right)
$$

or

$$
\frac{\Pi_{O}^{\text {Buм }}}{\Pi_{O}}=\theta^{\text {Buм }}+\beta_{O} \cdot T \square \frac{N_{O}^{B u м}}{N_{o}},
$$

where $\theta^{\text {BuM }}$ :

$$
\theta^{\text {Buм }}=\frac{\Pi_{O}^{\text {Buм }}}{\Pi_{O}}-\beta_{O} \cdot T
$$

The initial value of the production potential $\Pi_{o i}$ is calculated as follows:

$$
\Pi_{\text {oi }}=N_{\text {наявн } i} K_{e i} K_{\mathrm{Tp} i}
$$

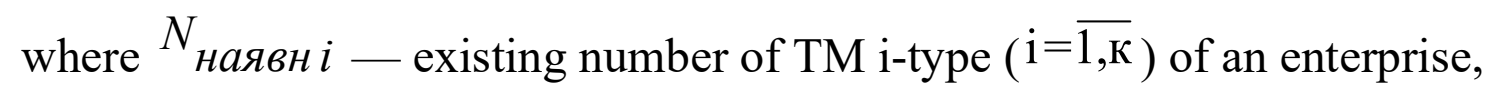
$K_{e i}$ - generalized operating factor of TM i-type of an enterprise:

$$
K_{e i}=K_{y \kappa i} \cdot K_{\text {тГ } i} \cdot K_{p e c} i
$$

In expression (5) ${ }^{K}{ }_{\text {pec }} i$ - resource stock ratio of TMT3 i-type of an enterprise,

$$
K_{\text {pec } i}=\frac{\sum_{\mathrm{s}=1}^{n} N_{i s} \cdot R_{i s}}{N_{\text {наявн } i}},
$$


where $N_{i s}$ - the number of TM of the i-type with the resource reserve factor $R_{i s \text { from existing }} N_{\text {наявн } i \text {; }}$

coefficient of technical readiness of TM of the i- type of the enterprise:

$$
K_{\mathrm{T \Gamma} i}=\frac{N_{\text {тГ } i}}{N_{\text {наявн } i}}
$$

$N_{\text {TГ } i}$ - the number of technically ready TM of the i- type;

$K_{y \kappa} i$ - the coefficient of staffing of the enterprise of the TM of the i-type

$$
K_{y \kappa i}=\frac{N_{\text {наявн } i}}{N_{\text {шт } i}}
$$

If $K_{y \kappa i}=1$, this means that the company has a 100 percent staffing of TM of the i- type.

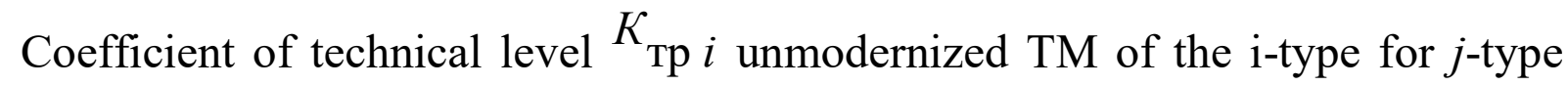
TCh $(\mathrm{j}=\overline{1, \mathrm{n}})$, of one or another, $z$-type, group $(\mathrm{z}=\overline{1, \mathrm{~m}})$ TCh given TM i-type in anticipation of modernization TCh given TM by comparing this characteristic with the corresponding characteristic TM, approved as standard E (for example, the best in the World):

$$
K_{\mathrm{Tp} j z i}=\frac{A_{j z i}}{A_{j z E}},
$$

where ${ }^{A} z i$ - numerical value $j$-type TCh of $z$-type group TCh TM $i$-type;

$A_{j z E}$ - numerical value of similar $j$-type TCh of $z$-type group TCh of standard TM.

Coefficient of technical level $K_{\text {Tp } z i}$ of all j-types $(\mathrm{j}=\overline{1, \mathrm{n}})$ TCh of $z$-type group of TCh of TM $i$-type is equal to:

$$
K_{\text {тр } z i}=K_{\text {тр } 1 i}=\sum_{\mathrm{j}=1}^{\mathrm{n}} K_{\operatorname{Tp} j 1 i} \cdot M_{j 1 i}=\sum_{\mathrm{j}=1}^{\mathrm{n}} \frac{A_{j 1 i}}{A_{j 1 E}} \cdot M_{j 1 i},
$$


wher ${ }^{M} j z i$ - coefficient of importance $j$-type $(\mathrm{j}=\overline{1, \mathrm{n}})$ TCh of $z$-type group TCh of TM of $i$-type, which is determined by an expert survey, in this case $\sum_{\mathrm{j}=1}^{\mathrm{n}} M_{j z i}=1$.

Thus, to ensure a given coefficient $\theta^{B u M}$ production capacity of the enterprise requires the value of potential $\Pi_{O}^{B u M}$ it is necessary to compare with the existing potential $\Pi_{O}$ of this enterprise before the beginning of a cycle of production activity in the conditions of average daily for the period $T$ relative losses $\beta_{O}$ TM of an enterprise.

In the future, it is assumed that the technical level of all TM of an enterprise with non-modernized TCh characterized by a generalized coefficient of technical level $K_{\mathrm{Tp}}$, which is defined as follows:

$$
K_{\mathrm{Tp}}=\frac{\sum_{\mathrm{i}=1}^{\mathrm{K}} K_{\mathrm{Tp}} i \cdot N_{\text {наявн } i}}{\sum_{\mathrm{i}=1}^{\mathrm{K}} N_{\text {наявн } i}}=\frac{\sum_{\mathrm{i}=1}^{\mathrm{K}} K_{\mathrm{Tp}} i \cdot N_{\text {наявн } i}}{N_{\text {наявн }}},
$$

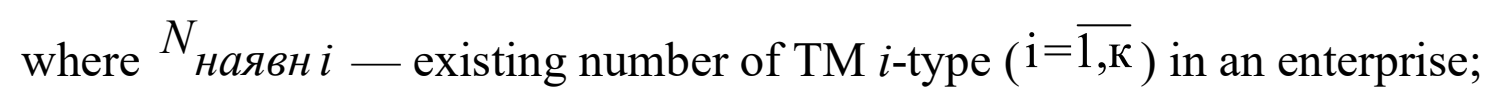

$N_{\text {наявн }}=\sum_{\mathrm{i}=1}^{\mathrm{K}} N_{\text {наявні }}$ - the total number of non-modernized TM of the enterprise, which consists of the number $N_{\text {наявн } i \text { TM } i \text {-type, some TCh which could }}$ be upgraded;

$K_{\mathrm{Tp}} i-$ coefficient of technical level of non-modernized TM of the i- type.

Even with the same amount $N_{\text {наявн } i \text { TMs of } i \text {-type the production potential of an }}$ enterprise will depend on the coefficient of the technical level $K_{\mathrm{Tp}}$ all its TMs, in particular, from the coefficient of the technical level $K_{\text {тр } i}$ ТМ of $i$-type. In turn, the

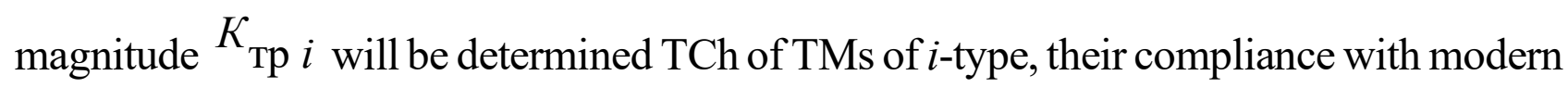
requirements, the degree of moral aging, which may necessitate the modernization of these TMs. 
The TMs modernization is performed by improving the technical characteristics. However, of course, not all TChs should improve, but only certain that can bring the greatest effect. Choosing the right set of characteristics is almost a separate task, as technical means can be characterized by a large number of TChs. Usually, a small amount (not more than 10) of TChs is selected for modernization, which characterizes the most important properties of the TMs, based on the planned (typical) method of TMs application. For example, a forklift truck is designed for truck work, but it is often used for short-distance transportation. When studying the effectiveness of each of these tasks, the appropriate list of TChs is selected.

In addition, to reduce the number of TChs, the full list of TChs can be divided into groups in quantity $\mathrm{m}(\mathrm{z}=\overline{1, \mathrm{~m}})$, based on the properties and functional purposes of the TM. Thus, for a forklift truck, the following groups can be considered separately $(\mathrm{z}=\overline{1, \mathrm{~m}}=1 \div 3)$ :

$\mathrm{z}=1$ - means of mobility;

$\mathrm{z}=2$ - means of loading;

$\mathrm{z}=3$ - means of transportation.

In each such group there may be several (for example, 5-6) the most significant TCh of the technical means.

We assume that each j-th TCh from the z-type group of TCh of the i- type has a numerical value ${ }^{A} j z i$ (measured in absolute units), and a similar j-type TCh with z-type group TCh of technical means of the i-type, which is conventionally taken as a standard, has a numerical value ${ }^{A} j z E$.

Then the coefficient of the technical leve $1 K_{\text {Tp } j z i}$ can be calculated according to the $\mathrm{j}$-type TCh $(\mathrm{j}=\overline{1, \mathrm{n}}) A_{j} z i$ from one or another, $\mathrm{z}$-type, group $(\mathrm{z}=\overline{1, \mathrm{~m}})$ TCh of a certain unmodernized TM of the i- type by comparing this characteristic with the corresponding characteristic ${ }_{j z} E$ of the TK taken as standard E:

$$
K_{\text {тр } j z i}=\frac{A_{j z i}}{A_{j z E}} .
$$


If we enter into consideration the coefficient of importance ${ }^{M} j i$ of the j-type $(\mathrm{j}=\overline{1, \mathrm{n}})$ of technical characteristic ${ }_{j} z i$ in relation to the selected TCh of the z-type group $(\mathrm{z}=\overline{1, \mathrm{~m}})$ of the TCh unmodernized TM of the $\mathrm{i}$ - type $(\mathrm{i}=\overline{1, \mathrm{~K}})$, which is determined by experience or expert survey, with $\sum_{\mathrm{j}=1}^{\mathrm{n}} M_{j z i}=1$, then for all $\mathrm{j}$-type $(\mathrm{j}=\overline{1, \mathrm{n}})$ TCh from the z-type group of technical characteristics of this TM, the coefficient of the technical level $K_{\mathrm{Tp} z} i$ will be equal to:

$$
K_{\text {тр } z i}=\sum_{\mathrm{j}=1}^{\mathrm{n}} K_{\mathrm{Tp}} z_{z i} \cdot M_{j z i}=\sum_{\mathrm{j}=1}^{\mathrm{n}} \frac{A_{j z i}}{A_{j z E}} \cdot M_{j z i}
$$

Note that the relationship $\frac{A_{j z i}}{A_{j z E}}$, taking into account the importance $M_{j z i \text { can be }}$ considered as conditional efficiency ${ }^{W} j i$ (due only to the characteristics of the TM of the i- type, which are selected for future modernization)

$$
W_{j z i}=K_{\mathrm{Tp} j z i} \cdot M_{j z i}=\frac{A_{j z i}}{A_{j z E}} \cdot M_{j z i}
$$

$j$-type TCh ${ }^{A} j z i$ of $z$-type group TCh of TM of the $i$-type relatively similar characteristics $A_{j z E}$ of standard TM, therefore it can be written as follows:

$$
K_{\text {тр } z i}=\sum_{\mathrm{j}=1}^{\mathrm{n}} K_{\mathrm{Tp}} j z i \cdot M_{j z i}=\sum_{\mathrm{j}=1}^{\mathrm{n}} \frac{A_{j z i}}{A_{j z E}} \cdot M_{j z i}=\sum_{\mathrm{j}=1}^{\mathrm{n}} W_{j z i} .
$$

It is possible to determine the importance of expert surveys $G_{z i}$ of selected $z$-type group from all $m$ groups of characteristics $(\mathrm{z}=\overline{1, \mathrm{~m}})$ of TM of the i-type, at the same time $\sum_{\mathrm{z}=1}^{\mathrm{m}} G_{z i}=1$.

Then the coefficient of the technical level $K_{\text {тр } i \text { for all z-type groups of TCh }}$ $(\mathrm{z}=\overline{1, \mathrm{~m}})$ of unmodernized TM of the i-type, calculated relative to the standard TM, will be equal to: 


$$
\begin{aligned}
& K_{\mathrm{Tp} i}=\sum_{\mathrm{z}=1}^{\mathrm{m}} K_{\mathrm{Tp} z i} \cdot G_{z i}=\sum_{\mathrm{z}=1}^{\mathrm{m}}\left(\sum_{\mathrm{j}=1}^{\mathrm{n}} K_{\mathrm{Tp}} j z i \cdot M_{j z i}\right) \cdot G_{z i}= \\
& =\sum_{\mathrm{z}=1}^{\mathrm{m}}\left(\sum_{\mathrm{j}=1}^{\mathrm{n}} \frac{A_{j z i}}{A_{j z E}} \cdot M_{j z i}\right) \cdot G_{z i}=\sum_{\mathrm{z}=1}^{\mathrm{m}} \sum_{\mathrm{j}=1}^{\mathrm{n}} W_{j z i} \cdot G_{z i}
\end{aligned}
$$

Thus, the coefficient of the technical level ${ }^{K}$ тр $i$ of every TM $i$ type is determined only by those selected to upgrade his TCh from all $z$ group $(z=\overline{1, m})$ given the importance of ${ }^{M}$ zi $j \mathrm{TCh}(\mathrm{j}=\overline{1, \mathrm{n}})$.

Similarly, the coefficient of the technical level can be determined $K_{\text {тр } i E \text { for all }}$ $\mathrm{z}$ groups of TCh $(\mathrm{z}=\overline{1, \mathrm{~m}})$ reference TM of the $\mathrm{i}$ type. But in this case, in relation to such vehicles can be considered, that ${ }_{j z i}={ }_{j z E}$. Then, taking into account the previously accepted values $M_{j z i}\left(\sum_{\mathrm{j}=1}^{\mathrm{n}} M_{j z i}=1\right), G_{z i}\left(\sum_{\mathrm{z}=1}^{\mathrm{m}} G_{z i}=1\right)$ it follows that

$$
K_{\text {тр } i E}=1 \text {, }
$$

that in the accepted conditions naturally.

For TM of all types $(i=\overline{1, K})$ the enterprise is determined by the generalized coefficient of the technical level of $K_{\mathrm{Tp}}$ unmodernized TM of all types, calculated relative to the reference $\mathrm{TM}$, considering:

$$
\begin{aligned}
& K_{\text {тр }}=\frac{\sum_{\mathrm{i}=1}^{\mathrm{K}} K_{\text {тр } i} \cdot N_{\text {наявн } i}}{\sum_{\mathrm{i}=1}^{\mathrm{K}} N_{\text {наявн }} i}=\frac{\sum_{\mathrm{i}=1}^{\mathrm{K}} N_{\text {наявн }} i \cdot \sum_{\mathrm{z}=1}^{\mathrm{m}} K_{\mathrm{Tp} z i} \cdot G_{z i}}{\sum_{\mathrm{i}=1}^{\mathrm{K}} N_{\text {наявн }} i}= \\
& =\frac{\sum_{\mathrm{i}=1}^{\mathrm{K}} N_{\text {наявн }} i \cdot \sum_{\mathrm{z}=1}^{\mathrm{m}}\left(\sum_{\mathrm{j}=1}^{\mathrm{n}} K_{\mathrm{Tp} j z i} \cdot M_{j z i}\right) \cdot G_{z i}}{\sum_{\mathrm{i}=1}^{\mathrm{K}} N_{\text {наявн } i}}= \\
& =\frac{\sum_{\mathrm{i}=1}^{\mathrm{K}} N_{\text {наявн }} i \cdot \sum_{\mathrm{z}=1}^{\mathrm{m}}\left(\sum_{\mathrm{j}=1}^{\mathrm{n}} \frac{A_{j z i}}{A_{j z E}} \cdot M_{j z i}\right) \cdot G_{z i}}{\sum_{\mathrm{i}=1}^{\mathrm{K}} N_{\text {наявн } i}}= \\
& =\frac{\sum_{\mathrm{i}=1}^{\mathrm{K}} N_{\text {наявн }} i \cdot \sum_{\mathrm{z}=1}^{\mathrm{m}} \sum_{\mathrm{j}=1}^{\mathrm{n}} W_{j z i} \cdot G_{z i}}{\sum_{\mathrm{i}=1}^{\mathrm{K}} N_{\text {наявн }} i}=\frac{\sum_{\mathrm{i}=1}^{\mathrm{K}} N_{\text {наявн }} i \cdot \sum_{\mathrm{z}=1}^{\mathrm{m}} \sum_{\mathrm{j}=1}^{\mathrm{n}} W_{j z i} \cdot G_{z i}}{N_{\text {наявн }}} .
\end{aligned}
$$


In this case, the coefficient of the technical level $K_{\mathrm{Tp}} \mathrm{TM}$ of all types and potential of the enterprise depends not only on TCh, but also from the available quantity of TM.

Similarly, the coefficient of the technical level is determined $K_{\mathrm{Tp}} i E$ reference TM of all types $(i=\overline{1, K})$ for all $\mathrm{z}$ groups of TCh $(\mathrm{z}=\overline{1, \mathrm{~m}})$ of enterprises, but taking into account:

$$
K_{\mathrm{Tp} E}=\frac{\sum_{\mathrm{i}=1}^{\mathrm{K}} N_{\text {наявн } i} \cdot K_{\mathrm{Tp} i E}}{\sum_{\mathrm{i}=1}^{\mathrm{K}} N_{\text {наявн } i}}=\frac{\sum_{\mathrm{i}=1}^{\mathrm{K}} N_{\text {наявн }} i}{\sum_{\mathrm{i}=1}^{\mathrm{K}} N_{\text {наявн }} i}=1 \text {, }
$$

which is also natural.

\section{CONCLUSIONS}

The article proposes a method for determining the required level of modernization of technical means of production at the enterprise, which provides an opportunity to formulate requirements for technical characteristics of means of production when equipping the enterprise with means of production. Among the advantages of the method is that, first, with its use it becomes possible to take into account the probable type of promising technical means of production equipment of the enterprise; secondly, the accuracy of the method allows to obtain correct forecast terms of TM replacement. 